\title{
Relationship Between Knowledge, Preventive Practices and Fear from COVID-19 among Middle Aged and Older Adults: During the Novel Coronavirus Outbreak
}

\author{
Sally Mohammed Elsayed Ibrahim ${ }^{1, ~ *, ~ M a r w a ~ A b d e l h a m i d ~ M o h a m m e d ~ M a h m o u d ~}{ }^{2}$ \\ ${ }^{1}$ Gerontological Nursing Department, Faculty of Nursing, Mansoura University, Mansoura, Egypt \\ ${ }^{2}$ Medical Surgical Nursing Department, Faculty of Nursing, Mansoura University, Mansoura, Egypt \\ Email address: \\ sallymohammed@mans.edu.eg (S. M. E. Ibrahim), marwaabdo@mans.edu.eg (M. A. M. Mahmoud) \\ ${ }^{*}$ Corresponding author
}

To cite this article:

Sally Mohammed Elsayed Ibrahim, Marwa Abdelhamid Mohammed Mahmoud. Relationship Between Knowledge, Preventive Practices and Fear from COVID-19 among Middle Aged and Older Adults: During the Novel Coronavirus Outbreak. American Journal of Nursing Science. Vol. 9, No. 5, 2020, pp. 333-346. doi: 10.11648/j.ajns.20200905.15

Received: August 25, 2020; Accepted: September 10, 2020; Published: September 21, 2020

\begin{abstract}
Background: New virus infections outbreaks among people are always a public health problem. For the COVID19, it may have physical, psychological, and social consequences that affect on individuals. One of these psychological consequences is fear. Older adults, especially with chronic health conditions are extremely vulnerable to COVID-19. So, individuals must have good COVID-19 knowledge and preventive practices to combat this fear and prevent the spread of infection Aim: Determine the relationship between knowledge, preventive practices, and fear from COVID-19 among middle aged and older adults: during the novel coronavirus outbreak. Design: A descriptive cross-sectional correlational research design was used in this study. Setting: The study was carried out at Temai Elamdid health insurance outpatient clinics that affiliated to the Egyptian Ministry of Health. Subjects: A convenience sample of 185 patients attending the previous study setting. Tools: Four tools were used in this study; demographic and clinical data structured interview schedule, COVID-19 knowledge structured interview schedule, COVID-19 preventive practices structured interview schedule and fear from COVID-19 scale Results: It was noticed that more than two fifth of middle aged adults and more than one third of older adults had satisfactory COVID-19 preventive practices, Furthermore, more than one third of middle aged adults and one third of older adults had good COVID-19 knowledge with statistically significant difference was found between two groups. Also, Significant relation was found between both COVID-19 knowledge and preventive practices and fear from COVID-19 among the study subjects $(\mathrm{P}=0.000)$. In the same direction, there was statistically significant difference between middle aged adults and older adults regarding COVID-19 knowledge and preventive practices and higher level of COVID-19 fear ( $\mathrm{P}=0.000)$. Conclusion: Older adults had a significant lower score of COVID-19 knowledge and preventive practices and higher level of COVID-19 fear than middle aged adults as strong negative correlation between fear from COVID-19 and either COVID-19 knowledge \& preventive practices was found. Recommendations: Educational programs should be developed and implemented by nurses in different care settings to increase their awareness about COVID-19.
\end{abstract}

Keywords: Knowledge, Preventive Practices, Fear, COVID-19, Middle Aged, Older Adults

\section{Introduction}

Coronaviruses are a large family of enveloped RNA viruses that mostly infect birds and mammals, with humans being particularly vulnerable to infection and transmission of the virus [51]. The previous outbreaks of coronaviruses such as Severe Acute Respiratory Syndrome-Coronavirus (SARS-
$\mathrm{CoV}$ ) and Middle East Respiratory Syndrome-Coronavirus (MERS-CoV) show similarities to the novel coronavirus [33]. The novel coronavirus disease 2019 (COVID-19) is an emerging respiratory disease that first reported in Wuhan, in the Hubei province of China in the late December 2019 when patients stated that they having viral pneumonia resulted from an unknown microbial pathogen. A new coronavirus 
was subsequently identified as the pathogen and was named temporarily the 2019 new coronavirus [36, 37].

The new COVID-19 epidemic has spread to most countries in the world. The number of new COVID-19 patients increased dramatically due to the traveling of hundreds of millions of people. The severity of COVID-19 had been underestimated until the national health commission classified it as a B type infectious disease and took actions to fight against this disease on 20 January 2020 [34]. Additionally, the World Health Organization (WHO) declared the COVID-19 outbreak a public health emergency of international concern on 30 January 2020 [56]. Since 31 December 2019 and as of 26 June 2020, 9581803 cases of COVID-19 (following the applied case definitions and testing strategies in the affected countries) have been reported worldwide, including 489182 deaths. In Egypt, 61 130 cases was reported till 26 June 2020 and a rapid tendency towards increase [57]. Although new COVID-19 seems to be very contagious and has quickly spread globally, most infected people will develop mild to moderate illness and recover without hospitalization. Fever and cough are suggesting the differences in viral tropism compared to, SARS-CoV, MERS-CoV, and influenza [9, 54, 14].

Clinical manifestations of the new COVID-19 included fever, cough, fatigue, muscle or body aches, difficulty breathing, sore throat, the new loss of taste or smell, and headache. Additionally, some patients manifested gastrointestinal symptoms, with diarrhea, nausea, and vomiting [17, 58]. Older adults due to frailty and week immunity and people who have severe underlying medical conditions like hypertension, chronic obstructive pulmonary disease, diabetes, and cardiovascular disease, seem to be at higher risk for developing more serious complications leading to death $[22,26]$. Atypical presentations of COVID19 in older adults may include delirium, abdominal pain, and low-grade fever [41].

Confirmation of cases of new COVID-19 is based on real time reverse transcription polymerase chain reaction (rRTPCR). Respiratory material should be collected from the upper respiratory specimens (nasopharyngeal and oropharyngeal swab or wash in ambulatory patients) and/or from the lower respiratory specimens (sputum if produced and/or endotracheal aspirate or bronchoalveolar lavage in patients with more severe respiratory disease [59] Regarding older adults, multiple lobe involvement was more common than in middle-aged [46].

Nowadays, there is no specific drug therapy against new COVID-19 for suspected or confirmed cases. Therefore, current treatments chiefly concentrated on symptomatic and respiratory support according to the diagnosis and treatment of pneumonia resulted from the new COVID-19 [38]. Almost all patients accepted oxygen therapy, and extracorporeal membrane oxygenation (ECMO) to patients with refractory hypoxemia is recommended by the World Health Organization [60]. Rescue treatment with convalescent plasma and immunoglobulin $\mathrm{G}$ is delivered to some critical cases [18]. It was noticed that older patients with COVID-19 have been reported to exhibit relatively higher mortality and severity of illness than younger patients [52] as the mortality rate of COVID-19 is $15 \%$ for older people 80 years or over compared to $0.2 \%$ for those under 20 years worldwide. Therefore, Age is considered a critical major risk for COVID-19 mortality as aging itself has been strongly associated with worse outcomes due to the pathophysiological changes that characterize the respiratory system and has created serious psychological disturbances, insecurity, and fear among older adults [28].

To date, there is no clinically approved vaccination against the new COVID-19. Therefore, the best prevention is to avoid being exposed to the virus through infection control measures [35]. The knowledge of the public is expected to largely influence the degree of adherence to personal protective measures [47]. The emergence of the COVID-19 and its pandemic nature has exacerbated fears worldwide. One characteristic nature of infectious disease compared with other conditions is fear [2]. Fear is known as an unpleasant emotional state that is induced by the perception of frightening stimuli [50]. Extraordinary situations such as disease outbreaks can trigger fear among many individuals $[6,25]$. Currently, there is not enough evidence that knowledge and preventive practices toward the COVID-19 influenced by fear from COVID-19 [62].

\subsection{Aims of the Study}

This study was aimed to determine the relationship between knowledge, preventive practices, and fear from COVID-19 among middle aged and older adults: during the novel coronavirus outbreak.

\subsection{Research Questions}

Q1: What is COVID-19 knowledge among middle aged and older adults: during the novel coronavirus outbreak?

Q2: What is COVID-19 preventive practices among middle aged and older adults: during the novel coronavirus outbreak?

Q3: What is the relationship between knowledge, preventive practices, and fear from COVID-19 among middle aged and older adults: during the novel coronavirus outbreak?

\section{Subject and Method}

\subsection{Study Design}

A descriptive cross-sectional correlational research design was used in this study.

\subsection{Setting}

The study was carried out at Temai Elamdid health insurance outpatient clinics that are affiliated to the Egyptian Ministry of Health.

Temai Elamdid health insurance outpatient clinics consisted of two floors. The ground consists of The 
pharmacy, The pharmacy store, Analysis Lab, an archive room that contains patients files, and finally two outpatient clinics; one general internal medicine clinic and the other general practitioner clinic for orthopedic, dermatology, and ophthalmology. The first floor consisted of director office, employee room, statistics office, medical supplies store, Paper store, bathroom, and two outpatient clinics (dentist clinic and pediatric clinic). The outpatient clinics receive patients (nearly 20 patients per day in each outpatient clinic due to novel coronavirus outbreak), six days per week from Saturday to Thursday from 8 Am to $2 \mathrm{Pm}$.

\subsection{Subjects}

A convenience sample of 185 patients. The sample size was calculated based on the percentage of inadequate knowledge about novel coronavirus among selected rural community $19 \%$ [45] and percentage of poor knowledge among general population $22.6 \%$ [21]. for calculating sample size we used the website "www.Dssresearch.com" using the previous percentage, two-tailed significance test with a power $80 \%$ and alpha error $5 \%$. The calculated sample size was 164 . We add $10 \%$ for any error in data calculation, So we were conducted our study on 185 patients attending the previous study setting and fulfilling the following (Inclusion criteria):

1) Able to communicate.

2) Willing and give their consent for participation in the study.

3) Available at the time of data collection.

4) Both sex patients.

5) Aged from 20 years old and older, and then stratified into two groups according to their age; Adults group (aged from 20 to less than 60 years old), and older adults group (aged from 60 years and more).

\subsection{Tools of Data Collection}

So as to collect the necessary information for the study, four tools were used:

\subsubsection{Tool I: Demographic and Medical History Structured Interview Schedule}

This tool was developed by the researchers after literature review [8, 43, 65] and consists of; demographic data of the study participants as age, sex, income, marital status, residence, occupation and education; as well as, medical history of study participants.

\subsubsection{Tool II: COVID-19 Knowledge Structured Interview Schedule}

This tool was developed by the researchers after the literature review $[64,24,61,15]$ to assess baseline knowledge of study participants about COVID-19. It consisted of thirty-two (32) multiple-choice questions; regarding the nature of the disease (Q1-Q2), mode of transmission (Q3-Q15), the incubation period (Q16), manifestations (Q17-Q19), diagnosis (Q20), treatment (Q21Q22), risk factors (Q23-Q24), complications (Q25), preventive measures (Q26-Q32). Each question was responded as Yes, No and I don't know.

Scoring system for COVID-19 knowledge structured interview schedule:

The correct answer for each question gets a score of one grade, while incorrect answers and don't know get a score of zero. The total knowledge score was computed out of thirtytwo (32) grades. It was converted into percent as the following [53]:

1) Good knowledge $=\geq 75 \%$.

2) Average knowledge $=50-75 \%$.

3) Poor knowledge $=<50 \%$.

\subsubsection{Tool III: COVID-19 Preventive Practices Structured Interview Schedule}

This tool was developed by the researchers after the literature review $[19,3,56]$ to assess COVID-19 preventive practices among study participants. It was consists of sixteen questions regarding; hand hygiene (Q1-Q2), avoid touching nose, mouth, and eye (Q3), wearing mask (Q4), disinfectant of surfaces (Q5), respiratory hygiene/cough etiquette (Q6Q7), social distancing (Q8-Q15) and self-isolation (Q16).

Scoring system for COVID-19 Preventive Practices structured interview schedule:

Give two grades for the answer "yes", one grade for the answer "sometimes", while zero for the answer "No" [39]. The total COVID-19 preventive practices score was computed out of thirty-two (32) grades. It was converted into percent.

The total COVID-19 Preventive practices score [53]:

1) Satisfactory practices $=\geq 75 \%$.

2) Unsatisfactory practices $=<75 \%$.

\subsubsection{Tool IV: Fear from COVID-19 Scale}

This scale was designed by Ahorsu et al.,(2020) [2]. It is originally designed to assess one's fear of COVID-19. It was in the English version and translated into the Arabic language and validated by the researchers. It consisted of seven questions. The subjects indicate their agreement level with the statements by a five-item Likert type scale. Answers included "strongly disagree," "disagree," "neither agree nor disagree," "agree," and "strongly agree". The maximum score possible for each question is five, and minimum the is one. A total score is calculated by adding up the score of each item (from seven to thirty-five). The higher the score, the greater COVID-19 fear.

\subsection{Method of Data Collection}

\subsubsection{Phase I: Preparatory Phase}

1) An Official approval which includes the title and aim of the study was obtained from the Faculty of Nursing, Mansoura University. Additionally, official approval for conducting the study was obtained from the responsible administrative personnel of Temai Elamdid health insurance outpatient clinics to attain the approval for interviewing the patients.

2) After a thorough review of the literature, Tool I (Demographic and medical history structured interview 
schedule), Tool II (COVID-19 knowledge structured interview schedule), Tool III (COVID-19 Preventive Practices structured interview schedule) were developed by the researchers.

3) Tool IV (Fear from COVID-19 scale) was translated by the researchers into the Arabic language and tested using the test-retest method.

4) The reliability of tool II \&tool III and Tool IV was applied to 20 patients selected from the previous mentioned setting and reapplied two weeks later. The reliability was assured by Cronbach's alpha (r) $r=0.89$ for tool II and $\mathrm{r}=0.88$ for tool III and $\mathrm{r}=0.87$ for tool IV.

5) The study tools were tested for its validity by seven experts in the fields of community health medicine and medical surgical nursing; as well as gerontological nursing, as a jury to test feasibility and validity, and the necessary changes were done consequently.

6) A pilot study was conducted on 20 patients (10\% of sample size) in the previously mentioned setting before beginning the data collection to test the tools feasibility and to make the necessary changes. Patients who participated in the pilot study were excluded from the study sample.

\subsubsection{Phase II: Operational Phase}

1) Based on the schedule of the Temai Elamdid health insurance outpatient clinics, the researchers visited the outpatient clinics six days per week (from Saturday to Thursday) from 8 Am to $2 \mathrm{Pm}$.

2) All patients who attended these clinics in these days and fulfill the study criteria were included in the study.

3) The researchers started by introducing herself to patients and giving him/her a brief idea about the study purpose.

4) Each patient who agreed to participate in the study and fulfilling the inclusion criteria was interviewed individually to collect the necessary data using all the study tools. Time taken to fill the study tools ranged from 20 to 30 minutes for each patient.

5) If the study subjects can't read the study questionnaire, the researchers read each question to study subjects and marked exactly the answer they gave.

6) The researchers used to meet with each study subject in the waiting room in outpatient clinics or inside outpatient clinics. A face to face interview was directed with each patient who achieved the study criteria. Then the required data were collected using tools of the study.

7) The researchers follow preventive measures while dealing with patients as wearing mask, gloves, maintain social distance, and prevent being in a crowded area with patients by interview patient individually according to the rules of outpatient clinics.

8) The data collection covered a period from the end of April, 2020 till the end of May, 2020.

\subsection{Ethical Consideration}

1) Informed consent from the study subjects was obtained after clarification of the study and assured that data collection was used only for the purpose of the study.

2) The confidentiality of the collected data and the privacy of the participants were maintained.

3) Study participants were informed about their rights to draw from the study at any time without any punishment.

\subsection{Statistical Analysis}

After data were collected it was revised, coded, and fed to Statistical Package for the Social Sciences (SPSS) version 22. The given graphs were constructed using Microsoft excel software and SPSS. The normality of data was first tested with one-sample Kolmogorov- Smirnov test. Data were presented using descriptive statistics in the form of frequencies and percentages for qualitative variables, and means and standard deviations, median, and Min-Max for quantitative variables. Quantitative continuous data were compared using the non-parametric Mann-Whitney U-test to compare quantitative variables between two groups and Kruskal-Wallis test for more than two groups and as the normal distribution of the data could not be assumed. Pearson correlation coefficient (r) used for the correlation between continuous data. Statistical significance was considered at $\mathrm{p}$ value $<0.05$.

\section{Results}

Table 1 shows the distribution of the studied subjects according to their demographic characteristics and their medical history, this study included 185 participants; half $(50.8 \%)$ of those were middle aged and about half (49.2\%) were older adults with a mean age 51.23 \pm 6.52 and $67.16 \pm 5.37$ respectively. Most of the two groups $(60.6 \%$ of middle aged and $61.5 \%$ of older adults) were male. Concerning the educational level the results revealed that diplome education was prevailing most of the two groups (48.9\% in middle aged and $37.4 \%$ in older adults group). Also, about half of both middle aged group and the older adults group were residing in urban $(52.1 \%$ \& $50.5 \%$ respectively). Regarding marital status, It was observed that about three quarter of middle aged (84\%) and about two third of older adults $(68.1 \%)$ were married. In relation to the economic status, the majority of both middle aged and older adults groups $(80.9 \%$ and $86.8 \%$ respectively) reported that their income was not enough. Regarding medical history, it was found that diabetes mellitus was the most prevailing disease among middle aged and older adults groups $(67 \%$ \& $68.1 \%$ respectively). With regard to demographic characteristics and medical history, there was no statistically significant difference between the two groups $(p>0.05)$ except occupation $(p=0.000)$.

Figure 1 illustrates the source of COVID-19 knowledge among middle aged and older adults, this figure shows that social media was considered the most common source of COVID-19 knowledge among both groups $(60.6 \%$ in middle aged and $40.7 \%$ in older adults), while the lowest source of 
knowledge among older adults was internet search (3.3\%), and among middle aged was health care workers (8.8\%).

Table 2 displays the distribution of studied subjects according to their knowledge \& preventive practices and fear from COVID-19, It was noticed that there was a statistically significant difference was found between middle aged group and older adults group regarding to COVID-19 knowledge as about one third of middle aged (37.2\%) and 33\% of older adults had good COVID-19 knowledge $(p=0.000)$. Also, it was observed that there was a statistically significant difference between middle aged and older adults groups. Concerning COVID-19 preventive practices, about two fifth (42.6\%) of middle aged group in comparison to about one third of older adults had satisfactory COVID-19 preventive practices $(p=0.000)$. Concerning fear from COVID-19, there was a statistically significant difference between middle aged and older adults groups as older adults had a higher level of fear than middle aged $(\mathrm{p}=0.000)$.

Table 3 shows the relation between demographic characteristics and both COVID-19 knowledge \& preventive practices among the studied subjects. It appears from the table that males obtain higher mean scores of COVID-19 knowledge and preventive practices than females in both middle aged and older adults groups $(\mathrm{P}=0.000)$. Furthermore, the was a statistically significant relation between residence and both COVID-19 knowledge and preventive practices among the studied subjects as study subjects who were residing in urban areas had both higher scores of COVID-19 knowledge and preventive practices than others in both middle aged and older adults groups $(p=0.000)$. Also, the table shows that there was a statistically significant relation between COVID-19 knowledge and income in both middle aged and older adults as the studied subjects with enough income had both higher scores of COVID-19 knowledge and preventive practices than those with not enough income $(\mathrm{P}=0.000)$. Moreover, the level of education affects significantly on COVID-19 knowledge in both groups as study subjects with university education had both higher scores of COVID-19 knowledge and preventive practices than others $(\mathrm{P}=0.000)$.

Table 4 shows the relation between demographic characteristics and Fear from COVID-19 among the studied subjects. It appears from the table that sex affects significantly on the level of fear as females had a higher level of fear than males in both middle aged and older adults groups $(\mathrm{P}=0.000)$. Concerning residence, there was a statistically significant relation between the residence of the studied subjects and level of fear as study subjects who were living in rural areas had a higher level of COVID-19 fear than those who were living in urban areas $(\mathrm{P}=0.000)$. Also, the table shows that there was a statistically significant relation between income and level of fear as the studied subjects with enough income had a higher level of fear than those with not enough income $(\mathrm{P}=0.000)$. Otherwise, results revealed that education level affect significantly on the level of COVID-19 fear as study subjects with university education had a lower level of fear than others $(\mathrm{P}=0.000)$.

Table 5 shows the relation between COVID-19 knowledge $\&$ preventive practices and fear from COVID-19 among the studied subjects, It was noticed from the table that there was statistically significant results between both COVID-19 knowledge and preventive practices and fear from COVID19 among the studied subjects as study subjects with good COVID-19 knowledge scores had a lower level of COVID19 fear than those with poor scores of COVID-19 knowledge $(\mathrm{P}=0.000)$. Moreover, study subjects with unsatisfactory COVID-19 preventive practices had a higher level of fear than those with satisfactory preventive practices scores in both middle aged and older adults groups $(\mathrm{P}=0.000)$.

Table 6 shows the relation between COVID-19 Knowledge and preventive practices among the studied subjects; it appears from the table that there were statistically significant results was found between study subjects COVID-19 knowledge and their preventive practices as study subjects with satisfactory COVID-19 preventive practices had higher knowledge about COVID-19 than those with unsatisfactory COVID-19 preventive practices in both middle aged and older adults groups $(\mathrm{P}=0.000)$.

Figures 2\&3 represent the correlation between total COVID-19 knowledge and preventive practices. These figures displayed that there was a statistically significant strong positive correlation between both total COVID-19 knowledge and preventive practices scores in middle aged and older adults groups.

Figures $4 \& 5$ show the correlation between total COVID19 knowledge scores and fear from COVID-19 scores of the studied subjects. The figures clarified that there was a statistically significant strong negative correlation was found between total COVID-19 knowledge scores and fear from COVID-19 scores in middle aged and older adults groups.

Figures $6 \& 7$ represent the correlation between total COVID-19 preventive practices scores and fear from COVID-19 scores in both middle aged and older adults groups. These figures revealed that there was a statistically significant strong negative correlation between total COVID19 preventive practices scores and fear from COVID-19 scores among the study subjects.

Table 1. Demographic characteristics and medical history of middle aged and older adults groups.

\begin{tabular}{llllll}
\hline \multirow{2}{*}{ Items } & \multicolumn{2}{l}{ Middle-aged group } & \multicolumn{2}{l}{ Older adults group } & Test of significance \\
\cline { 2 - 5 } & $\mathbf{N}$ & $\mathbf{9}$ & $\mathbf{N}$ & $\mathbf{\%}$ & \\
\cline { 2 - 5 } & $\mathbf{9 4}$ & $\mathbf{5 0 . 8}$ & $\mathbf{9 1}$ & $\mathbf{4 9 . 2}$ & \\
\hline Age (years) & $51.23+6.52$ & & $67.16+5.37$ & & \\
Sex & & & & & \\
Male & 57 & 60.6 & 56 & 61.5 & $\mathrm{Z}=0.125$ \\
Female & 37 & 39.4 & 35 & 38.5 & $\mathrm{P}=0.900$ \\
\hline
\end{tabular}




\begin{tabular}{|c|c|c|c|c|c|}
\hline \multirow{3}{*}{ Items } & \multicolumn{2}{|c|}{ Middle-aged group } & \multicolumn{2}{|c|}{ Older adults group } & \multirow[t]{3}{*}{ Test of significance } \\
\hline & $\mathbf{N}$ & $\%$ & $\mathbf{N}$ & $\%$ & \\
\hline & 94 & 50.8 & 91 & 49.2 & \\
\hline \multicolumn{6}{|l|}{ Residence } \\
\hline Urban & 49 & 52.1 & 46 & 50.5 & $Z=0.214$ \\
\hline Rural & 45 & 47.9 & 45 & 49.5 & $\mathrm{P}=0.830$ \\
\hline \multicolumn{6}{|l|}{ Occupation } \\
\hline Employee & 51 & 54.3 & 0 & 0 & \\
\hline Worker & 12 & 12.8 & 0 & 0 & \\
\hline Housewife & 19 & 20.2 & 23 & 25.3 & $\mathrm{X} 2=72.323$ \\
\hline Farmer & 4 & 4.3 & 5 & 5.5 & $\mathrm{P}=0.000^{*}$ \\
\hline Retired & 0 & 0 & 58 & 63.7 & \\
\hline Private work & 8 & 8.5 & 5 & 5.5 & \\
\hline \multicolumn{6}{|l|}{ Marital Status } \\
\hline Single & 2 & 2.1 & 0 & 0 & \\
\hline Married & 79 & 84.0 & 62 & 68.1 & $X 2=13.597$ \\
\hline Divorced & 4 & 4.3 & 2 & 2.2 & $\mathrm{P}=0.214$ \\
\hline Widow & 9 & 9.6 & 27 & 29.7 & \\
\hline \multicolumn{6}{|l|}{ Education } \\
\hline Illiterate & 11 & 11.7 & 25 & 27.5 & \multirow{5}{*}{$\begin{array}{l}\mathrm{X} 2=8.201 \\
\mathrm{P}=0.084\end{array}$} \\
\hline Read and write & 11 & 11.7 & 10 & 11 & \\
\hline Primary education & 16 & 17.0 & 16 & 17.6 & \\
\hline Diplome & 46 & 48.9 & 34 & 37.4 & \\
\hline University & 10 & 10.6 & 6 & 6.6 & \\
\hline \multicolumn{6}{|l|}{ Income } \\
\hline Enough & 18 & 19.1 & 12 & 13.2 & $Z=1.097$ \\
\hline Not enough & 76 & 80.9 & 79 & 86.8 & $\mathrm{P}=0.273$ \\
\hline \multicolumn{6}{|l|}{ Medical History } \\
\hline \multicolumn{6}{|l|}{ Hypertension } \\
\hline Yes & 29 & 30.9 & 36 & 39.6 & $Z=-1.237$ \\
\hline No & 65 & 69.1 & 55 & 60.4 & $\mathrm{P}=0.216$ \\
\hline \multicolumn{6}{|l|}{ Diabetes Mellitus } \\
\hline Yes & 63 & 67.0 & 62 & 68.1 & $Z=-0.161$ \\
\hline No & 31 & 33.0 & 29 & 31.9 & $\mathrm{P}=0.872$ \\
\hline \multicolumn{6}{|l|}{ Liver cirrhosis } \\
\hline Yes & 10 & 10.6 & 12 & 13.2 & $Z=-0.534$ \\
\hline No & 84 & 89.4 & 79 & 86.8 & $\mathrm{P}=0.593$ \\
\hline \multicolumn{6}{|c|}{ Ischemic Heart disease } \\
\hline Yes & 27 & 28.7 & 34 & 37.4 & $Z=-1.246$ \\
\hline No & 67 & 71.3 & 57 & 62.6 & $\mathrm{P}=0.213$ \\
\hline
\end{tabular}

\# means more than one response; $\mathrm{Z}$ value of Mann-Whitney $\mathrm{U}$ test; $\mathrm{X} 2$ value of Kruskal-Wallis test;

*Significant at $\mathrm{P} \leq 0.05$

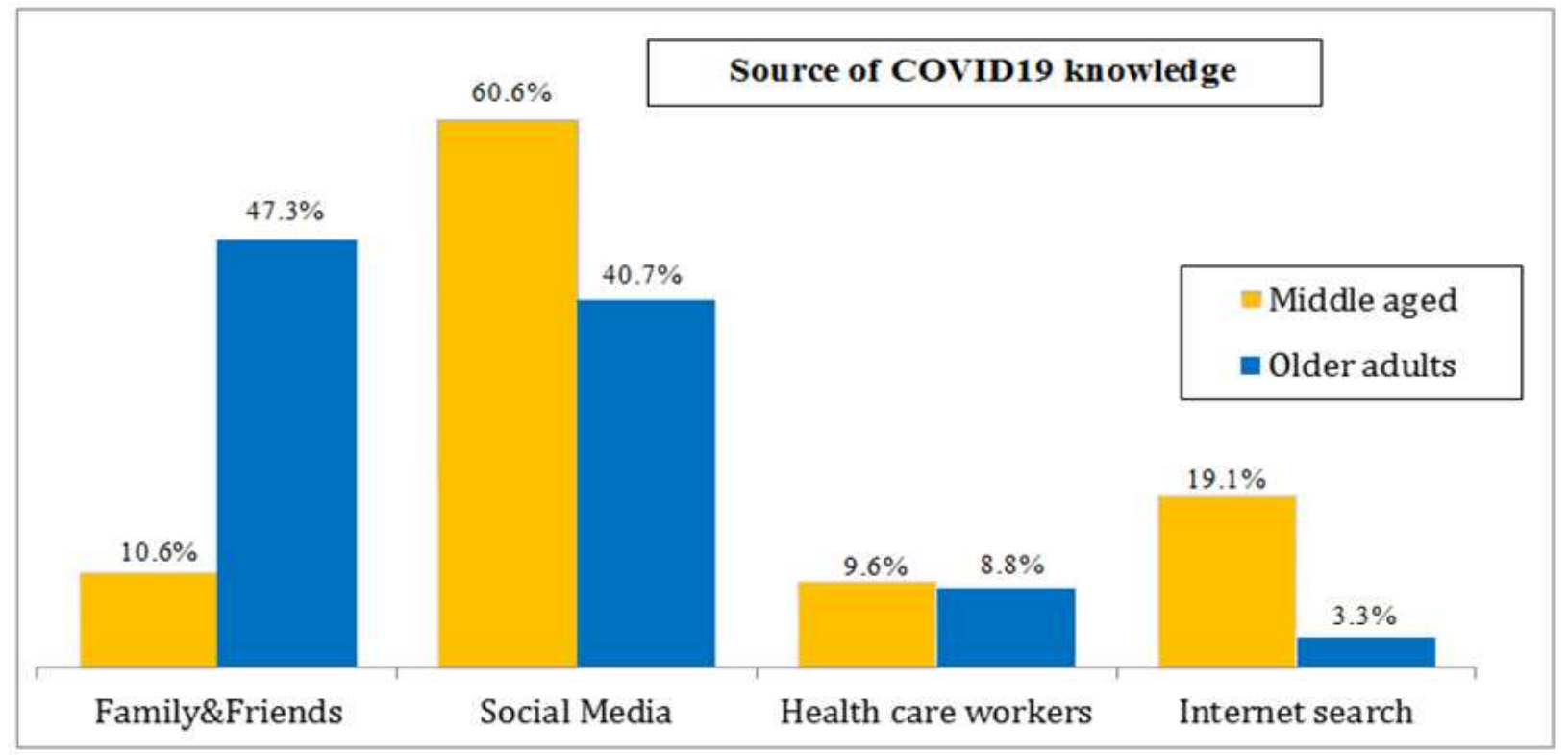

Figure 1. Source of COVID-19 knowledge among middle aged and older adults. 
339 Sally Mohammed Elsayed Ibrahim and Marwa Abdelhamid Mohammed Mahmoud: Relationship Between Knowledge, Preventive Practices and Fear from COVID-19 among Middle Aged and Older Adults: During the Novel Coronavirus Outbreak

Table 2. Distribution of studied subjects according to knowledge \&preventive practices and fear from COVID-19.

\begin{tabular}{|c|c|c|c|c|c|c|}
\hline \multirow{2}{*}{ Items } & \multicolumn{2}{|c|}{ Middle-aged group } & \multicolumn{2}{|c|}{ Older adults group } & \multicolumn{2}{|c|}{ Mann-Whitney U test } \\
\hline & N (94) & $\%$ & $\mathbf{N}(91)$ & $\%$ & $\mathbf{Z}$ & $\mathbf{p}$ \\
\hline \multicolumn{7}{|c|}{ COVID-19 Knowledge } \\
\hline Good & 35 & 37.2 & 30 & 33.0 & \multirow{5}{*}{-4.123} & \multirow{5}{*}{$(0.000) *$} \\
\hline Average & 17 & 18.1 & 11 & 12.1 & & \\
\hline Poor & 42 & 44.7 & 50 & 54.9 & & \\
\hline Mean $\pm \mathrm{SD}$ & \multirow{2}{*}{\multicolumn{2}{|c|}{$\begin{array}{l}20.52 \pm 6.95 \\
23(10-30)\end{array}$}} & \multicolumn{2}{|c|}{$16.74 \pm 7.36$} & & \\
\hline Median (Min-Max) & & & $14(7-$ & & & \\
\hline Satisfactory & 40 & 42.6 & 32 & 35.2 & \multirow{4}{*}{-4.677} & \multirow{4}{*}{$(0.000) *$} \\
\hline Unsatisfactory & 54 & 57.4 & 59 & 64.8 & & \\
\hline Mean \pm SD & \multirow{2}{*}{\multicolumn{2}{|c|}{$\begin{array}{l}23.99 \pm 4.43 \\
23(15-30)\end{array}$}} & \multicolumn{2}{|c|}{$20.99 \pm 5.53$} & & \\
\hline Median (Min-Max) & & & $21(12$ & & & \\
\hline \multicolumn{7}{|l|}{ Fear from COVID-19 } \\
\hline Mean \pm SD & \multicolumn{2}{|c|}{$12.33 \pm 5.22$} & \multicolumn{2}{|c|}{$20.74 \pm 6.59$} & \multirow{2}{*}{-8.088} & \multirow{2}{*}{$(0.000) *$} \\
\hline Median (Min-Max) & $10(7-2$ & & $23(10$ & & & \\
\hline
\end{tabular}

*Significant at $\mathrm{p} \leq 0.05$

Table 3. Relation between demographic characteristics and both COVID-19 Knowledge \& preventive practices among the studied subjects.

\begin{tabular}{|c|c|c|c|c|c|c|c|c|}
\hline \multirow{3}{*}{$\begin{array}{l}\text { Demographic } \\
\text { characteristics }\end{array}$} & \multicolumn{4}{|c|}{ COVID-19 Knowledge } & \multicolumn{4}{|c|}{ COVID-19 preventive practices } \\
\hline & \multicolumn{2}{|c|}{ Middle-aged group $(\mathrm{N}=94)$} & \multicolumn{2}{|c|}{ Older adults group $(\mathrm{N}=91)$} & \multicolumn{2}{|c|}{ Middle-aged group $(\mathrm{N}=94)$} & \multicolumn{2}{|c|}{ Older adults group $(\mathrm{N}=91)$} \\
\hline & Mean \pm SD & $\begin{array}{l}\text { Median } \\
\text { (Min-Max) }\end{array}$ & Mean \pm SD & $\begin{array}{l}\text { Median } \\
\text { (Min-Max) }\end{array}$ & Mean \pm SD & $\begin{array}{l}\text { Median } \\
\text { (Min-Max) }\end{array}$ & Mean \pm SD & $\begin{array}{l}\text { Median } \\
\text { (Min-Max) }\end{array}$ \\
\hline \multicolumn{9}{|l|}{ Sex } \\
\hline Male & $25.29 \pm 4.42$ & $28(14-30)$ & $20.84+6.19$ & $25(12-28)$ & $26.75 \pm 2.65$ & $28(22-30)$ & $24.41 \pm 3.54$ & $27(18-28)$ \\
\hline Female & $13.16 \pm 1.55$ & $14(10-15)$ & $10.17+3.04$ & $10(7-17)$ & $19.73 \pm 3.01$ & $20(15-23)$ & $15.51 \pm 3.27$ & $15(12-22)$ \\
\hline Urban & $26.73 \pm 2.47$ & $28(23-30)$ & $22.96+4.83$ & $25(14-28)$ & $27.43 \pm 2.20$ & $28(23-30)$ & $25.59 \pm 2.69$ & $27(21-28)$ \\
\hline Rural & $13.76 \pm 2.37$ & $14(10-22)$ & $10.38+2.27$ & $11(7-14)$ & $20.24 \pm 2.96$ & $22(15-23)$ & $16.29 \pm 3.24$ & $17(12-22)$ \\
\hline Test of significance & $Z=-8.432$ & $\mathrm{P}=0.000^{*}$ & $Z=-8.181$ & $\mathrm{P}=0.000^{*}$ & $Z=-8.007$ & $\mathrm{P}=0.000 *$ & $Z=-7.970$ & $\mathrm{P}=0.000^{*}$ \\
\hline \multicolumn{9}{|l|}{ Marital Status } \\
\hline Single & $30.00 \pm 0.00$ & $30(30-30)$ & & & $29.50 \pm 0.71$ & $29.5(29-30)$ & & \\
\hline Married & $24.50 \pm 7.00$ & $28(14-28)$ & $25.50+0.71$ & $25.5(25-26)$ & $26.75 \pm 3.20$ & $28(22-29)$ & $27.00 \pm 0.00$ & $27(27-27)$ \\
\hline Widow & $16.89 \pm 5.73$ & $14(12-27)$ & $13.70+6.99$ & $11(7-28)$ & $24.01 \pm 4.43$ & $23(15-30)$ & $21.97 \pm 5.19$ & $22(12-28)$ \\
\hline Test of significance & $X 2=10.522$ & $\mathrm{P}=0.015$ & $\mathrm{X} 2=8.568$ & $\mathrm{P}=0.014$ & $X 2=9.542$ & $\mathrm{P}=0.023$ & $X 2=9.155$ & $\mathrm{P}=0.010$ \\
\hline \multicolumn{9}{|l|}{ Occupation } \\
\hline Employee & $23.59 \pm 6.19$ & $27(12-30)$ & & & $26.43 \pm 2.94$ & $28(19-30)$ & & \\
\hline Private work & $22.00 \pm 8.40$ & $28(10-28)$ & $16.80 \pm 8.84$ & $19(7-25)$ & $22.08 \pm 3.15$ & $23(17-29)$ & & \\
\hline Farmer & $13.16 \pm 1.83$ & $14(10-15)$ & $9.35 \pm 2.74$ & $9(7-17)$ & $18.68 \pm 2.93$ & $18(15-23)$ & $14.44 \pm 2.79$ & $14(12-22)$ \\
\hline Worker & $18.08 \pm 5.66$ & $15(12-30)$ & & & $22.75 \pm 0.50$ & $23(22-23)$ & $20.60 \pm 3.29$ & $20(18-26)$ \\
\hline Housewife & $20.75 \pm 4.50$ & $23(14-23)$ & $15.00 \pm 5.61$ & $13(12-25)$ & $24.50 \pm 5.88$ & $28(15-29)$ & $20.20 \pm 7.33$ & $22(12-27)$ \\
\hline Retired & & & $19.81 \pm 6.56$ & $20(11-28)$ & & & $23.69 \pm 3.99$ & $24(17-28)$ \\
\hline Test of significance & $X 2=28.758$ & $\mathrm{P}=0.000^{*}$ & $X 2=42.501$ & $\mathrm{P}=0.000^{*}$ & $X 2=41.511$ & $\mathrm{P}=0.000^{*}$ & $X 2=43.584$ & $\mathrm{P}=0.000^{*}$ \\
\hline \multicolumn{9}{|l|}{ Education } \\
\hline Illiterate & $12.36 \pm 3.53$ & $11(10-22)$ & $9.20+2.68$ & $9(7-17)$ & $17.46 \pm 3.21$ & $16(15-23)$ & $14.28 \pm 2.73$ & $14(12-22)$ \\
\hline Read and write & $15.91 \pm 4.59$ & $14(12-23)$ & $12.00+2.49$ & $11(11-19)$ & $19.27 \pm 2.79$ & $18(17-23)$ & $17.80 \pm 1.55$ & $17(17-22)$ \\
\hline University & $24.50 \pm 5.93$ & $27.5(12-30)$ & $28.00+0.00$ & $28(28-28)$ & $26.80 \pm 3.22$ & $28(19-29)$ & $28.00 \pm 0.00$ & $28(28-28)$ \\
\hline Test of significance & $X 2=39.568$ & $\mathrm{P}=0.000^{*}$ & $\mathrm{X} 2=69.258$ & $\mathrm{P}=0.000^{*}$ & $X 2=51.645$ & $\mathrm{P}=0.000^{*}$ & $X 2=68.247$ & $\mathrm{P}=0.000^{*}$ \\
\hline \multicolumn{9}{|l|}{ Income } \\
\hline Enough & $22.49 \pm 6.23$ & $23.5(10-14)$ & $18.15+6.86$ & $16(9-28)$ & $25.66 \pm 3.01$ & $28(20-30)$ & $22.29 \pm 4.72$ & $22(14-28)$ \\
\hline Not enough & $12.22 \pm 1.56$ & $12.5(12-30)$ & $7.42+0.51$ & $7(7-8)$ & $16.94 \pm 1.59$ & $17(15-20)$ & $12.42 \pm 0.67$ & $12(12-14)$ \\
\hline Test of significance & $Z=-6.049$ & $\mathrm{P}=0.000^{*}$ & $Z=5.577$ & $\mathrm{P}=0.000^{*}$ & $Z=-6.708$ & $\mathrm{P}=0.000 *$ & $Z=-5.578$ & $\mathrm{P}=0.000^{*}$ \\
\hline
\end{tabular}

$Z$ value of Mann-Whitney U test;

X2 value of Kruskal-Wallis test;

*Significant at $\mathrm{P} \leq 0.05$ 
Table 4. Relation between demographic characteristics and Fear from COVID-19 among the studied subjects.

\begin{tabular}{|c|c|c|c|c|}
\hline \multirow{3}{*}{ Demographic characteristics } & \multicolumn{4}{|c|}{ Fear from COVID-19 } \\
\hline & \multicolumn{2}{|c|}{ Middle-aged group ( $\mathrm{N}=94)$} & \multicolumn{2}{|c|}{ Older adults group $(\mathrm{N}=91)$} \\
\hline & Mean \pm SD & Median (Min-Max) & Mean \pm SD & Median (Min-Max) \\
\hline \multicolumn{5}{|l|}{ Sex } \\
\hline Male & $8.72 \pm 1.54$ & $8(7-13)$ & $17.04 \pm 5.28$ & $15(10-25)$ \\
\hline Female & $17.89 \pm 3.76$ & $18(13-25)$ & $26.66 \pm 3.32$ & $27(19-30)$ \\
\hline Test of significance & $Z=-8.190$ & $\mathrm{P}=0.000^{*}$ & $Z=-7.198$ & $\mathrm{P}=0.000^{*}$ \\
\hline \multicolumn{5}{|l|}{ Residence } \\
\hline Urban & $8.27 \pm 1.09$ & $8(7-10)$ & $14.98 \pm 3.68$ & $13.5(10-23)$ \\
\hline Rural & $16.76 \pm 4.22$ & $16(11-25)$ & $26.62 \pm 2.19$ & $26(23-30)$ \\
\hline Test of significance & $Z=-8.398$ & $\mathrm{P}=0.000^{*}$ & $Z=-8.221$ & $\mathrm{P}=0.000^{*}$ \\
\hline \multicolumn{5}{|l|}{ Occupation } \\
\hline Employee & $9.55 \pm 2.82$ & $8(7-19)$ & 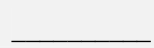 & 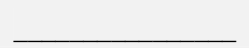 \\
\hline Worker & $13.58 \pm 4.582$ & $10(10-13)$ & & \\
\hline Housewife & $19.37 \pm 3.22$ & $19(13-25)$ & $27.52 \pm 2.95$ & $28(19-30)$ \\
\hline Farmer & $10.75 \pm 1.50$ & $8(8-24)$ & 22. $60 \pm 4.28$ & $24(15-25)$ \\
\hline Private work & $12.25 \pm 7.03$ & $12(7-21)$ & $21.40 \pm 7.50$ & $18(15-30)$ \\
\hline Retired & & & $17.83 \pm 5.69$ & $16(10-26)$ \\
\hline Test of significance & $\mathrm{X} 2=35.649$ & $\mathrm{P}=0.000^{*}$ & $X 2=29.164$ & $\mathrm{P}=0.000^{*}$ \\
\hline \multicolumn{5}{|l|}{ Marital Status } \\
\hline Single & $7.00 \pm 0.00$ & $7(7-7)$ & 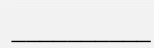 & 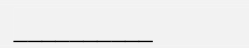 \\
\hline Married & $12.39 \pm 5.22$ & $10(7-25)$ & $19.79 \pm 6.33$ & $21.5(10-30)$ \\
\hline Widow & $14.67 \pm 5.19$ & $13(8-22)$ & $23.44 \pm 6.51$ & $26(11-30)$ \\
\hline Divorced & $8.50 \pm 3.00$ & $7(7-13)$ & $13.50 \pm 0.71$ & $13.5(13-14)$ \\
\hline Test of significance & $\mathrm{X} 2=10.901$ & $\mathrm{P}=0.012$ & $\mathrm{X} 2=8.198$ & $\mathrm{P}=0.017$ \\
\hline \multicolumn{5}{|l|}{ Education } \\
\hline Illiterate & $20.27 \pm 5.22$ & $22(11-25)$ & $27.68 \pm 2.88$ & $29(19-30)$ \\
\hline Read and write & $16.64 \pm 4.78$ & $19(10-21)$ & $25.00 \pm 2.49$ & $26(18-26)$ \\
\hline Primary education & $14.25 \pm 3.53$ & $16(7-18)$ & $20.81 \pm 4.61$ & $24(14-25)$ \\
\hline Diplome & $9.70 \pm 3.86$ & $8(7-15)$ & $16.09 \pm 4.33$ & $13.5(12-24)$ \\
\hline University & $9.30 \pm 2.41$ & $8.5(7-19)$ & $10.83 \pm 0.75$ & $11(10-12)$ \\
\hline Test of significance & $X 2=47.024$ & $\mathrm{P}=0.000^{*}$ & $\mathrm{X} 2=69.451$ & $\mathrm{P}=0.000 *$ \\
\hline \multicolumn{5}{|l|}{ Income } \\
\hline Enough & $21.17 \pm 2.20$ & $21(18-25)$ & $29.42 \pm 0.51$ & $29(29-30)$ \\
\hline Not enough & $10.24 \pm 3.08$ & $9(7-18)$ & $19.42 \pm 6.06$ & $20(10-29)$ \\
\hline Test of significance & $Z=-6.605$ & $\mathrm{P}=0.000^{*}$ & $Z=-5.533$ & $\mathrm{P}=0.000^{*}$ \\
\hline
\end{tabular}

$Z$ value of Mann-Whitney $U$ test;

$\mathrm{X} 2$ value of Kruskal-Wallis test;

*Significant at $\mathrm{P} \leq 0.05$

Table 5. Relation between COVID-19 knowledge \& preventive practices and fear from COVID-19 among the studied subjects.

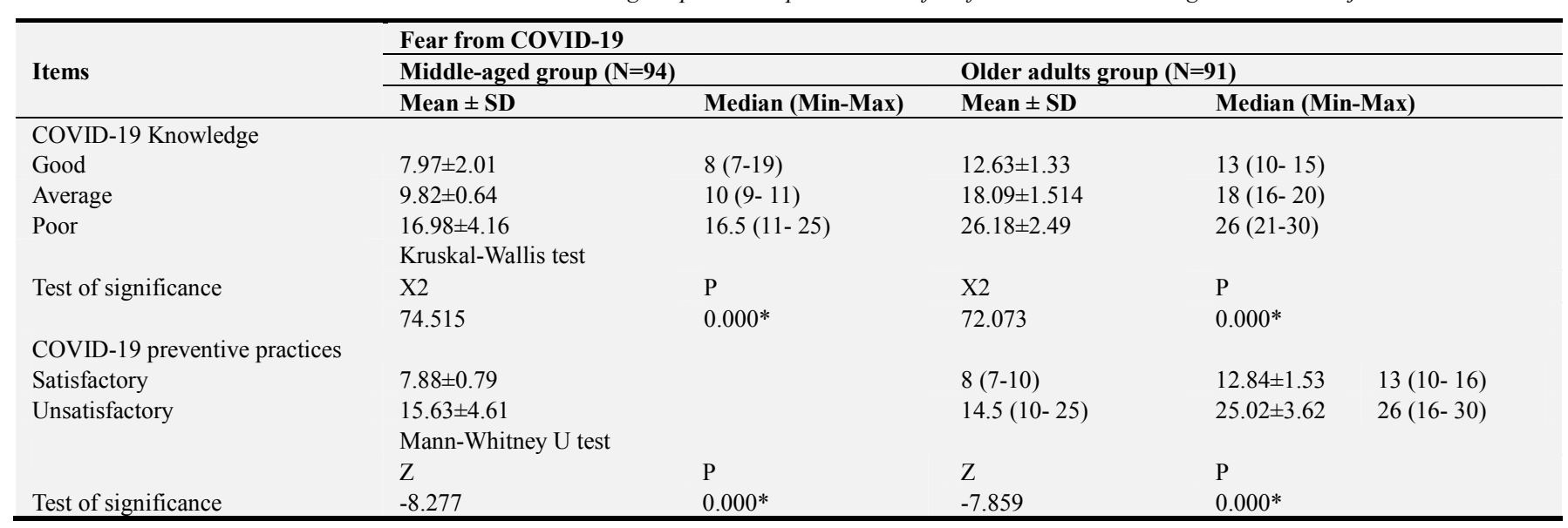

*Significant at $\mathrm{P} \leq 0.05$ 
341 Sally Mohammed Elsayed Ibrahim and Marwa Abdelhamid Mohammed Mahmoud: Relationship Between Knowledge, Preventive Practices and Fear from COVID-19 among Middle Aged and Older Adults: During the Novel Coronavirus Outbreak

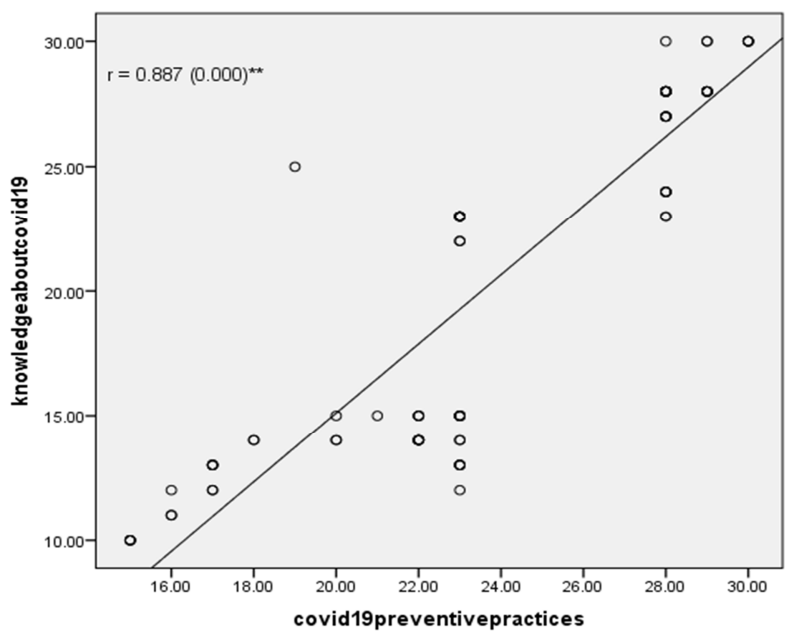

Figure 2. Correlation between total scores of COVID-19 knowledge and preventive practices among middle aged group.

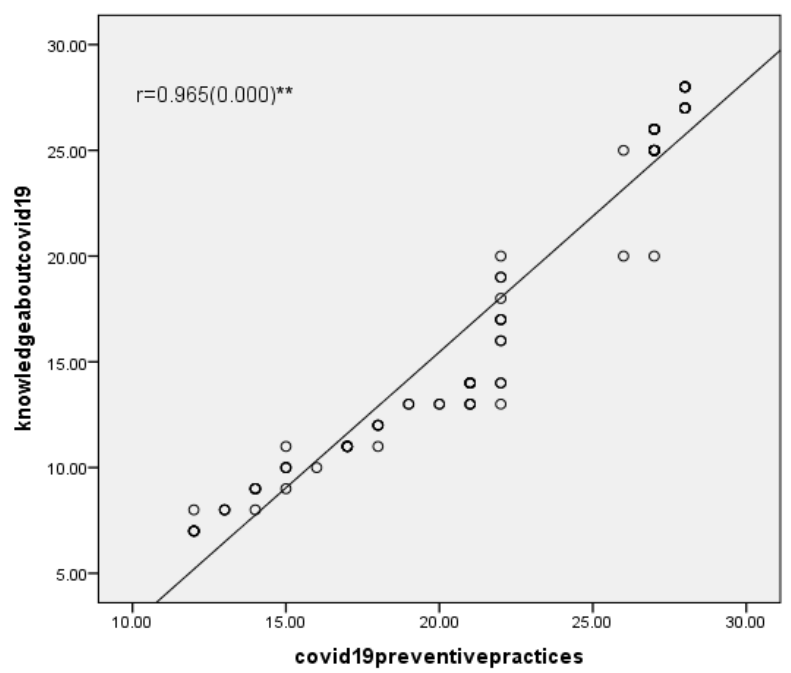

Figure 3. Correlation between total scores of COVID-19 knowledge and preventive practices among older adults group.

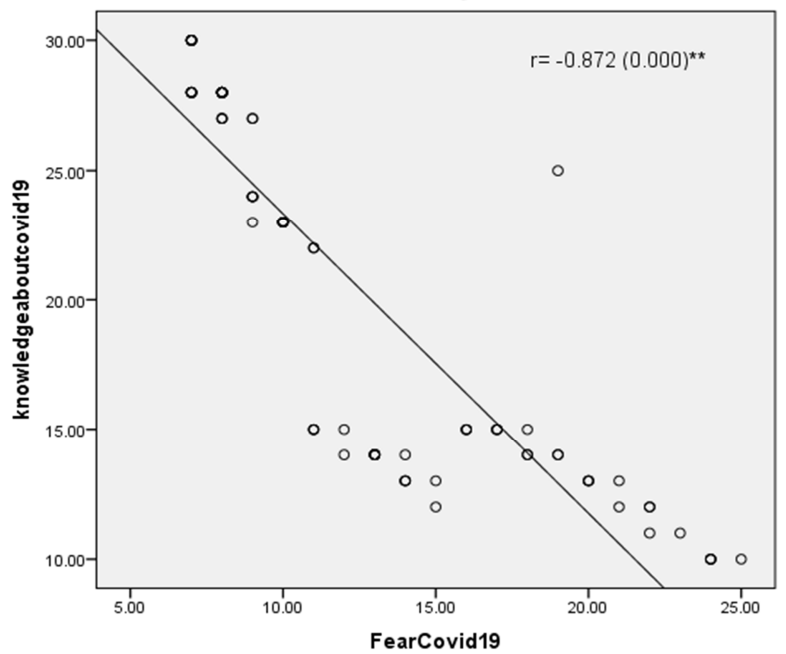

Figure 4. Correlation between total scores of COVID-19 knowledge and fear from COVID-19 among middle aged group.

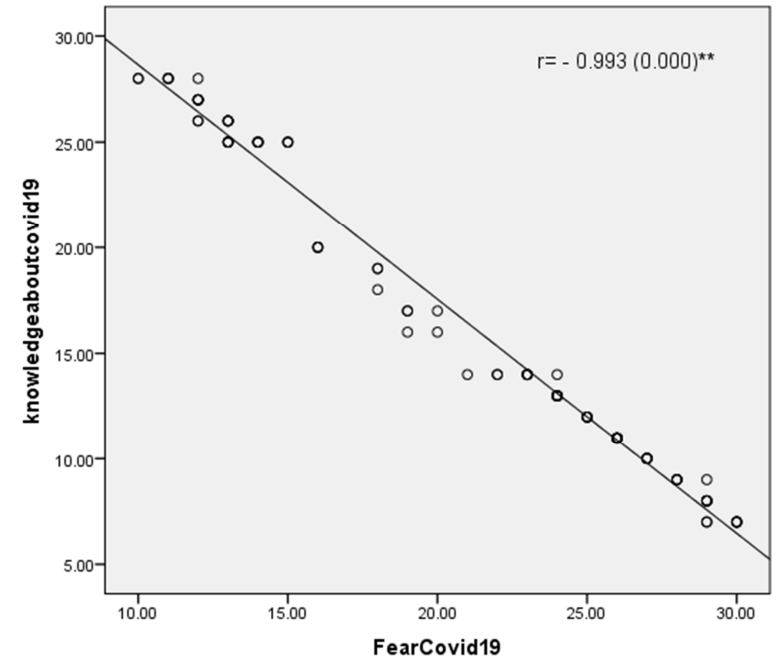

Figure 5. Correlation between total scores of COVID-19 knowledge and fear from COVID-19 among older adults group.

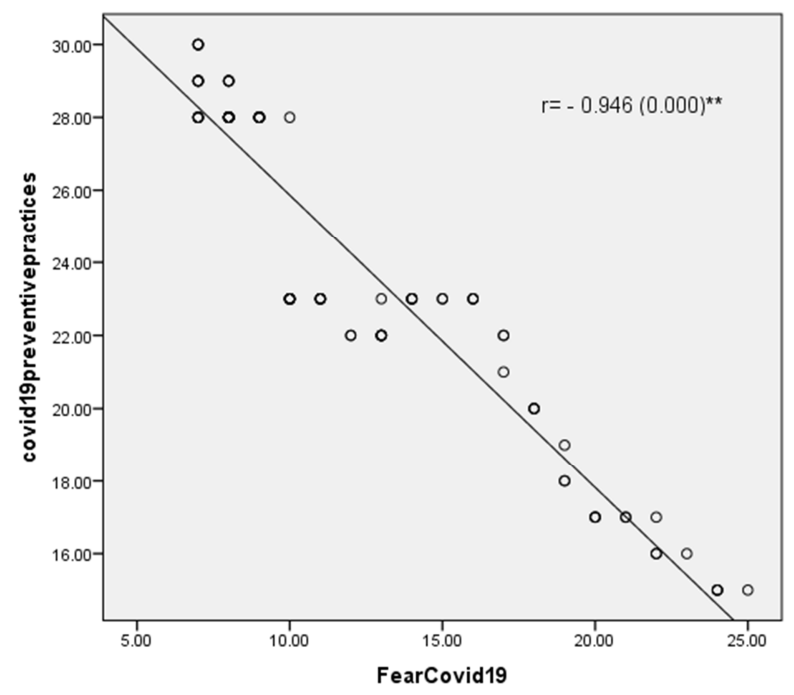

Figure 6. Correlation between total scores of COVID-19 preventive practices and fear from COVID-19 among middle aged group.

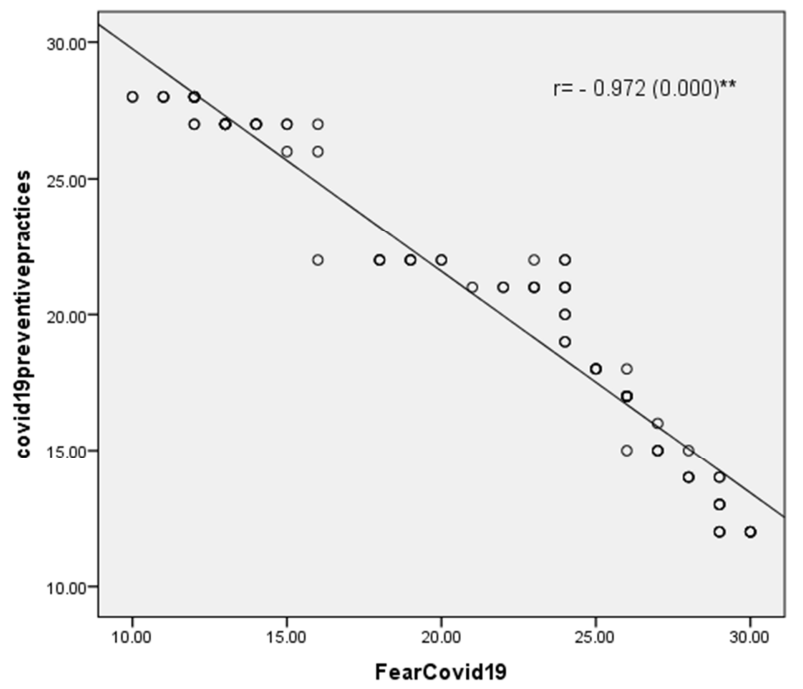

Figure 7. Correlation between total scores of COVID-19 preventive practices and fear from COVID-19 among older adults group. 
Table 6. Relation between COVID-19 knowledge and preventive practices among the studied subjects.

\begin{tabular}{|c|c|c|c|c|}
\hline \multirow{3}{*}{ Items } & \multicolumn{4}{|c|}{ COVID-19 Knowledge } \\
\hline & \multicolumn{2}{|c|}{ Middle-aged group (N=94) } & \multicolumn{2}{|c|}{ Older adults group $(\mathrm{N}=91)$} \\
\hline & Mean \pm SD & Median (Min-Max) & Mean \pm SD & Median (Min-Max) \\
\hline \multicolumn{5}{|c|}{ COVID-19 preventive practices } \\
\hline Satisfactory & $27.58 \pm 1.89$ & $28(23-30)$ & $25.84 \pm 1.90$ & $26(20-28)$ \\
\hline \multirow[t]{2}{*}{ Unsatisfactory } & $15.29 \pm 4.08$ & $14(10-23)$ & $11.79 \pm 3.39$ & $11(7-20)$ \\
\hline & \multicolumn{4}{|c|}{ Mann-Whitney U test } \\
\hline \multirow[t]{2}{*}{ Test of significance } & $\mathrm{Z}$ & $\mathrm{P}$ & Z & $\mathrm{P}$ \\
\hline & 8.276 & $0.000 *$ & 8.117 & $0.000 *$ \\
\hline
\end{tabular}

*Significant at $\mathrm{P} \leq 0.05$

\section{Discussion}

Coronavirus disease 2019 (COVID-19) is a novel disease that has caused numerous effects on publics' daily life unusually. A sudden outbreak of new COVID-19 has happened since December 2019 in Wuhan City, Hubei Province, a central city in the people's republic of China, where transference is tremendously suitable to attaching all other places inside China and outside it precisely African countries like Algeria, Nigeria and Egypt Qian et al., [42].

As the World Health Organization has declared the fastspreading of COVID-19 as an epidemic Saadat et al., [48]. The main step to fight any infectious disease pandemic in nature is to evaluate knowledge and preventive practices about the disease. Simultaneously, the effect of a pandemic on psychological responses such as fear Doshi et al. [20]. Therefore; this study was aimed to determine knowledge, preventive practices, and fear toward COVID-19 among middle aged and older adults: during the novel coronavirus outbreak.

Regarding demographic characteristics and medical history of the studied subjects, the current study showed that most of the participants of the two groups either middle aged or older adults were male. It is in the same line with Kebede et al., [32] who stated that more than three fourths of respondents were male. In contrast, Azlan et al., [10] reported that more than half of the participants were female. From the researchers' point of view, this difference may be due to variation in the sample size of participants.

Concerning the educational level, the results of this study revealed that diplome education was prevailing most of the two groups. This finding is in contrast with a study carried out by Geldsetzer., [23] who stated that Bachelor's degree was prevailing among participants. This may be related to the distinction of setting and different nature of studied subjects. Regarding participants' medical history, it was found that diabetes mellitus was the most prevailing disease among middle aged and older adults groups. These results agree with Wolf et al., [55] who said that more than half of participants have diabetes mellitus.

As regard to the source of COVID-19 knowledge among middle aged and older adults, the present study showed that social media was considered the most common source of COVID-19 knowledge among both groups, this result is in accordance with Abdelhafiz et al. [1] who found that the most commonly stated sources of COVID-19 knowledge were social media. In addition, Olaimat et al., [40] stated that social media was the most common source of knowledge about COVID-19. Additionally, Bhagavathula et al., [12] reported that the main source of COVID-19 information was social media. This may be due to social media have a wide range of channels as television, radio, and so on. Also, it is available at any time and easy to access.

Concerning knowledge, preventive practices, and fear from COVID-19, It was noticed that there was a statistically significant difference was found between middle aged group and older adults groups regarding COVID-19 knowledge as about two fifths of middle aged group had good COVID-19 knowledge compared to one third of older adults. This coincides with a study conducted in Egypt by Abdelhafiz et al. [1] who emphasized that the mean knowledge score about COVID-19 was significantly lower among older participants. This finding may be due to that most of the older adults during the COVID-19 outbreak live alone and no one visits them to increase their awareness about COVID-19. Also, most of the older adults were had a lower educational level than middle aged.

In relation to COVID-19 preventive practices, the current study showed that there was a statistically significant difference was found between middle aged group and older adults group as more than two fifths of middle aged group had satisfactory COVID-19 preventive practices in comparison with more than one third of older adults group. It is in the same direction with Zhong et al., [64] who reported that older adults are more likely to have inappropriate preventive practices towards COVID-19. Additionally, Salman et al., [49] revealed that geriatric populations would be more likely to have poor knowledge and preventive practices. These results are inconsistent with a study done in the Kingdom of Saudi Arabia by Al-Hanawi et al., [4] who found that older adults are likely to have better knowledge and practices than younger people. This may be due to most of the older adults in our study who had low socioeconomic status as most of them retired which discourage them to be compliant with COVID-19 preventive practices.

Regarding fear from COVID-19, the current study showed that there was a statistically significant difference was found 
between middle aged group and older adults group as older adults had a higher level of fear than middle aged. This come in accordance with Guterres., [27] who said that the COVID19 pandemic is causing untold fear and suffering for older adults across the world. These results may be due to older adults are twice as likely to have serious COVID-19 Centers for disease control and prevention [16]. This is expected because as people age, their immune systems change, making it harder for their body to fight off infection and diseases, and because many older adults are also more likely to have health conditions that make it harder to cope with and recuperate from. Age increases the risk that the lungs or respiratory system will shut down when an older person has COVID-19 disease Cameron., [13].

Concerning the relation between demographic characteristics and both COVID-19 knowledge \& preventive practices among the studied subjects, the current study revealed that males obtain higher mean scores of COVID-19 knowledge \& preventive practices than females in middle aged and older adults groups. It is in accordance with a study conducted by Almofada et al., [6] who revealed that males had a higher percentage of COVID-19 knowledge compared to females. However, these results contrast withAl-Hanawi et al., [4] who reported that males have less knowledge and less good practice toward COVID-19 than females. Additionally, Hezima et al., [30] found that female participants obtain higher mean scores of COVID-19 knowledge than male participants $(\mathrm{P}=0.001)$.

As regard to residence, the current study revealed that there was statistically significant relation was found between residence and both COVID-19 knowledge \& preventive practices among the studied subjects as study subjects who were residing in urban areas had both higher scores of COVID-19 knowledge and preventive practices than others in both middle aged and older adults group. It is in the same line with Zhong et al., [64] who revealed that rural people with low income are more likely to have poor knowledge, negative attitudes, and inappropriate preventive practices towards COVID-19. Besides, Salman et al., [49] reported that rural populations would be more likely to have poor knowledge and preventive practices.

Concerning income, the current study revealed that there was a statistically significant relation between both COVID19 knowledge \& preventive practices among the studied subjects as the studied subjects with enough income had both higher scores of COVID-19 knowledge and preventive practices than others in both middle aged and older adults group. It is agreed with a study done in Egypt by Abdelhafiz et al. [1] who reported that COVID-19 Knowledge was significantly lower among lower-income participants. Additionally, Azlan et al., [10] reported that higher knowledge scores were obtained among participants in the higher income category as subjects with a high income had money to shop masks, gloves, and other preventive equipment than others.

As detected from this study results regarding the level of education, it was obvious that study subjects with university education had both higher scores of COVID-19 knowledge and preventive practices than others. It is consistent with Zegarravaldivia et al., [63] who highlighted that Well-educated people have a better understanding of control measures and preventive strategies related to COVID-19. Additionally, Al-Mohrej et al., [7] as well as, Bawazir et al., [11] reported that more educated participants are more knowledgeable regarding preventive measures of diseases than others.

Concerning the relation between demographic characteristics and fear from COVID-19 among the studied subjects, the current study revealed that female and lower educational level participants had a higher level of fear than male and university education participants in both middle aged and older adults groups. It is in the same line with Doshi et al., [20] who reported that females and lower educational status displayed significantly higher odds for a high level of fear compared to their respective counterparts in this study population.

Regarding the relation between residence and fear from COVID-19 among the studied subjects, the current study revealed that study subjects who were living in rural areas had a higher level of COVID-19 fear than those who were living in urban areas. Otherwise, a study was done in Bangladesh by Hossain et al., [31] revealed that Dhaka urban dwellers reported a higher status of COVID-19 fear than rural dwellers this may due to subjects in a rural area had fewer health centers and had difficult to access health centers than who residing in urban, so they fear from acquiring disease than others. Also, the present study showed that there was a statistically significant strong negative correlation between fear from COVID-19 and either total Knowledge about COVID-19 scores \& total COVID-19 preventive practices scores in both middle aged and older adults groups. It was in the same line with Hossain et al., [31] who reported that knowledge scores showed contrasting correlation with Fear scores. In contrast, Ali et al., [5] didn't find a correlation between fear and knowledge.

Concerning the relation between total COVID-19 knowledge scores and preventive practices scores among both middle aged and older adults groups. The study revealed that there was a statistically significant strong positive correlation between total COVID-19 knowledge scores and preventive practices scores among study subjects this may due to when an individual had good knowledge about COVID-19 they aware of complications and serious consequences of the disease so they practice preventive measures better than individual with poor knowledge It is agreed with Rahman\& Sathi., [44] who found a positive correlation between the COVID-19 knowledge scores and Preventive practices scores, So a good knowledge is important for a better practice toward COVID-19. On the other hand, a study was conducted in Egypt by Hamza et al., [29] who revealed that no correlation appeared to exist between COVID-19 knowledge and practice. Finally, these previous findings highlight the importance of assessing knowledge, preventive practices, and fear toward COVID-19 among middle aged and older adults: during the novel coronavirus outbreak. 


\section{Conclusion}

Based on the findings of the current study, it can be concluded that social media was considered the most common source of COVID-19 knowledge among both middle aged and older adults groups. Middle aged adults had a significantly high score of COVID-19 knowledge and preventive practices and lower level of COVID-19 fear than older adults as a strong negative correlation between fear from COVID-19 and either COVID-19 knowledge \& preventive practices were found. This finding indicates that increase awareness about COVID-19 and how to prevent it important for decreasing the level of COVID-19 fear.

\section{Recommendations}

Based on the results of the present study the following recommendations are suggested:

1) Educational programs should be planned and implemented by nurses in different care settings regarding COVID-19 and providing the public with educational materials as; books, pamphlets, and videos to increase their awareness about COVID-19 and promoting their COVID-19 preventive practices to stop its spread.

2) Development and implementation of psychological rehabilitation programs for the public to alleviate their COVID-19 fear and help them to cope with novel coronavirus outbreak.

3) Future researches are needed to assess factors that affecting COVID-19 knowledge, preventive practices, and level of COVID-19 fear.

\section{Acknowledgements}

We would like to thank all studied participants as well as health personnel in the Temai Elamdid health insurance outpatient clinics that affiliated to the ministry of health, Egypt for their participation to fulfill this study.

\section{References}

[1] Abdelhafiz A., Mohammed Z., Ibrahim M., Ziady H., Alorabi M., Ayyad M. and Sultan E. (2020): Knowledge, Perceptions, and Attitude of Egyptians Towards the Novel Coronavirus Disease (COVID-19), Journal of Community Health. https://doi.org/10.1007/s10900-020-00827-7.

[2] Ahorsu D., Lin C., Imani V., Saffari M., Griffiths M. and Pakpour A. (2020): The Fear of COVID-19 Scale: Development and Initial Validation. International Journal of Mental Health and Addiction, 1-9. Advance online publication. https://doi.org/10.1007/s11469-020-00270-8.1

[3] Al Ahdab S. (2020): Knowledge, Attitudes and Practices (KAP) towards pandemic COVID-19 among Syrians. Europe PMC Journal available at https://europepmc.org/article/ppr/ppr170078 accessed on 8 April 2020.
[4] Al- Hanawi M., Angawi Kh., Alshareef N., Qattan A., Helmy H., Abudawood Y., Alqurashi M., Kattan W., Kadasah N., Chirwa G. and Alshariq O. (2020): Knowledge, Attitude and Practice Toward COVID-19 Among the Public in the Kingdom of Saudi Arabia: A Cross-Sectional Study; 8: 217. DOI: $10.3389 /$ fpubh. 2020.00217.

[5] Ali M., Zakir Uddin M., Banik P., Hegazy F., Zaman Sh., Ambia S., Siddique M., Islam R., Khanam F., Bahalul S., Sharker M., Hossain F. and Ahsan G. (2020): Knowledge, attitude, practice and fear of COVID-19: A cross-cultural study, available at https://www.researchgate.net/publication/341677849 accessed at 28 July, 2020.

[6] Almofada S., Alherbisch R., Almuhraj N., Almeshary B., Alrabiah B., Alsaffan A. and Baseer M. (2020): Knowledge, Attitudes, and Practices Toward COVID-19 in a Saudi Arabian Population: A Cross-Sectional Study, Cureus; 12 (6): e8905. DOI: $10.7759 /$ cureus.8905.

[7] Al-Mohrej O., Al-Shirian S., Al-Otaibi S., TamimH., Masuadi E. and Fakhoury H., (2016): Is the Saudi public aware of Middle East respiratory syndrome?, J Infect Public Health; 9: 259-66.

[8] Asaad A., El-Sokkary R., Alzamanan M., and El-Shafei M. (2020): Knowledge and attitudes towards Middle East respiratory syndrome-coronavirus (MERS-CoV) among health care workers in south-western Saudi Arabia. Eastern Mediterranean Health Journal; 25.

[9] Assiri A., Al-Tawfiq J., Al-Rabeeah A., Al-Rabiah F., AlHajjar S., Al-Barrak A., et al. (2013): Epidemiological, demographic, and clinical characteristics of 47 cases of Middle East respiratory syndrome coronavirus disease from Saudi Arabia: a descriptive study, Lancet Infect Dis; 13 (9): 752-61.

[10] Azlan A., Hamzah M., Sern Th., Ayub S. and Mohamad E. (2020): Public knowledge, attitudes and practices towards COVID-19: A cross-sectional study in Malaysia, available on: https://doi.org/10.1371/journal.pone.0233668, accessed at 24 July, 2020.

[11] Bawazir A., Al-Mazroo E., Jradi H., Ahmed A. and Badri M. (2018): MERS-CoV infection: mind the public knowledge gap, J Infect Public Health; 11: 89-93.

[12] Bhagavathula A., Aldhaleei W., Rahmani J., Mahabadim A. and Bandari D., (2020): Knowledge and perceptions of COVID-19 among health care workers: cross-sectional study. JMIR Public Heal Surveill; 6 (2): e19160. DOI: $10.2196 / 19160$.

[13] Cameron K. (2020): UPDATED: Coronavirus: What Older Adults Need to Know, available on: https://www.ncoa.org/blog/coronavirus-what-older-adults-needto-know/, accessed at 23 July, 2020.

[14] Cascella M., Rajnik M., Cuomo A., Dulebohn S. and Napoli R., (2020): Features, Evaluation and Treatment Coronavirus (COVID-19) available at https://www.ncbi.nlm.nih.gov /books/NBK554776/ accessed at 26 June, 2020.

[15] Centers for disease control and prevention (2020): Coronavirus disease 2019 (COVID-19) available at https://www.cdc.gov/coronavirus/2019ncov/about/transmission.html accessed on $3^{\text {rd }}$ March 2020. 
345 Sally Mohammed Elsayed Ibrahim and Marwa Abdelhamid Mohammed Mahmoud: Relationship Between Knowledge, Preventive Practices and Fear from COVID-19 among Middle Aged and Older Adults: During the Novel Coronavirus Outbreak

[16] Centers for Disease Control and Prevention (2020): Older Adults, available on: https://www.cdc.gov/coronavirus/2019ncov/need-extra-precautions/older-adults.html accessed at 23 July, 2020.

[17] Centers for Disease Control and Prevention (2020): Symptoms of Coronavirus available at https://www.cdc.gov/coronavirus/2019-ncov/symptomstesting/symptoms.html, accessed at 27 June, 2020.

[18] Chen L., Xiong J., Bao L. and Shi Y. (2020): Convalescent plasma as a potential therapy for COVID-19, Lancet Infect Dis. https://doi.org/10.1016/s1473-3099(20)30141-9.

[19] Delshad M., Pourhaji F., Pourhaji F., Ghanbarizadeh S., Zarmehri H., Bazrafshan E. and Aval G.(2020): Community responses during early phase of the COVID-19 epidemic: a crosssectional study. MedRxiv Journal available at https://www.medrxiv.org/content/10.1101/2020.04.04.200535 46v1 accessed on 11 April 2020.

[20] Doshi D., Karunakar P., Sukhabogi J., Prasanna J. and Mahajan Sh. (2020): Assessing Coronavirus Fear in Indian Population Using the Fear of COVID-19 Scale, International Journal of Mental Health and Addiction, Springer Science+Business Media, LLC, part of Springer Nature. https://doi.org/10.1007/s11469-020-00332-x.

[21] Erfani A., Shahriarirad R., Ranjbar K., Mirahmadizadeh A. and Moghadami M.(2020): Knowledge, Attitude and Practice toward the Novel Coronavirus (COVID-19) Outbreak: A Population-Based Survey in Iran. Bull of the World Health Organ. E-pub: 30 March 2020 available at http://dx.DOI.org/10.2471/BLT.20.251561 accessed on 3 April 2020.

[22] Garnier-Crussard A., Forestier E., Gilbert T. and KrolakSalmon P. (2020): Novel Coronavirus (COVID - 19) Epidemic: What Are the Risks for Older Patients?. Ameriacan Geriatric Society Journal; $0(0)$.

[23] Geldsetzer P. (2020): Knowledge and Perceptions of COVID19 Among the General Public in the United States and the United Kingdom: A Cross-sectional Online Survey available on: https://www.acpjournals.org/10.7326/M20-091223871, accessed at 22 July, 2020.

[24] Giao H., Han N., Khanh T., Ngan V., Tam V and An P. (2020): Knowledge and attitude toward COVID-19 among healthcare workers at District 2 Hospital, Ho Chi Minh City. Asian Pacific Journal of Tropical Medicine; 13 (6): 260-265.

[25] Griffiths D. and Mamun A. (2020): COVID-19 suicidal behavior among couples and suicide pacts: Case study evidence from press reports. Psychiatry Research. 289. availabe at https://www.ncbi.nlm.nih.gov/pmc/articles/PMC7229970/\# accessed on 22 May 2020.

[26] Guo R., Cao D., Hong S., Tan Y., Chen D., Jin J., Tan S., Wang Y. and Yan Y. (2020): The origin, transmission and clinical therapies on coronavirus disease 2019 (COVID-19) outbreak - an update on the status. Military Medical Research; 7 (11). https://doi.org/10.1186/s40779-020-00240-0.

[27] Guterres A. (2020): "Our response to COVID-19 must respect the rights and dignity of older people", available on: https://www.un.org/en/coronavirus/our-response-covid-19must-respect-rights-and-dignity-older-people, accessed at 23 July, 2020.

[28] Gyasi R., Phillips D. and Buor D. (2020): The Role of a
Health Protection Scheme in Health Services Utilization Among Community-Dwelling Older Persons in Ghana. The Journals of Gerontology; 75 (3): 661-673.

[29] Hamza M., Badary, O. and Elmazar M. (2020): CrossSectional Study on Awareness and Knowledge of COVID-19 Among Senior pharmacy Students, Journal of Community Health. https://doi.org/10.1007/s10900-020-00859-z.

[30] Hezima A., Aljafari A., Aljafari A., Mohammad, A. and Adel I. (2020): Knowledge, attitudes, and practices of Sudanese residents towards COVID-19, East Mediterr Health Journal; 26 (6): 646-651. https://doi.org/10.26719/emhj.20.076.

[31] Hossain A., Hossain M., Walton M., Zakir Uddin M., Obaidul Haque M., Feroz Kabir M., Arafat Y., Sakel M., Faruqui R., Jahid K. and Hossain Z. (2020): Knowledge, Attitudes, and Fear of COVID-19 during the Rapid Rise Period in Bangladesh, available https://www.medrxiv.org/content/10.1101/2020.06.17.201336 $11 \mathrm{v} 1$, accessed at 28 July, 2020.

[32] Kebede Y., Yitayih Y., Birhanu Z., Mekonen S. and Ambelu A. (2020): Knowledge, perceptions and preventive practices towards COVID-19 early in the outbreak among Jimma university medical center visitors, Southwest Ethiopia, PLoS One; 15 (5): e0233744.

[33] Li Y., You Z., Wang Q., Zhou J., Qiu Y., Luo R. and Ge Y. (2020): The epidemic of 2019-novel-coronavirus (2019-nCoV) pneumonia and insights for emerging infectious diseases in the future, Microbes and Infection; 22 (2), 80-85. https://doi.org/10.1016/j.micinf.2020.02.002.

[34] Li S., Wang W., Xue J., Zhao N. and Zhu T. (2020): The Impact of COVID-19 Epidemic Declaration on Psychological Consequences: A Study on Active Weibo Users, International Journal of Environmental Research and Public Health; 17 (6): 2032. DOI: 10.3390/ijerph17062032.

[35] Li C., Bai Z. and Hashikawa T. (2020): The neuroinvasive potential of SARS-CoV2 may play a role in the respiratory failure of COVID-19 patients, Journal of Medical Virology. https://doi.org/10.1002/jmv.25728.

[36] Lu H., Stratton W. and Tang W. (2020): Outbreak of pneumonia of unknown etiology in Wuhan China: the mystery and the miracle, J Med Virol.; 92. DOI: 10.1002/jmv. 25678.

[37] Lu R., Zhao X., Li J., Niu P., Yang B., Wu H., Wang W., Song H., Huang B., Zhu N., Bi Y., Ma X. Zhan F., Wang L., $\mathrm{Hu}$ T. and Zhou H. (2020): Genomic characterisation and epidemiology of 2019 novel coronavirus: implications for virus origins and receptor binding. Lancet.; 395: 565-74.

[38] National Health Commission of the People's Republic of China (2020): Diagnosis and Treatment of Pneumonia Caused by $2019-\mathrm{nCoV}$, version 6 . available at http://www.gov.cn/zhengce/zhengceku/202002/19/content_5480948.htm. accessed at 27 June, 2020.

[39] Nour M., Babilghith A., Natto H., Al-Amin F. and Alawneh S. (2015): Knowledge, attitude and practices of healthcare providers towards MERS-CoV infection at Makkah hospitals, KSA. International Research Journal of Medicine and Medical Sciences; 3 (4): 103-112.

[40] Olaimat A., Aolymat I., Shahbaz H. and Holley R. (2020): Knowledge and Information Sources About COVID-19 Among University Students in Jordan: A Cross-Sectional Study, Front. Public Health; 8: 254. DOI: 10.3389/fpubh.2020.00254. 
[41] Perrotta F., Corbi G., Mazzeo G., Boccia Matilde., Aronne L., D'Agnano V., Komici K., Mazzarella G., Parrella 5 R. and Bianco A. (2020): COVID-19 and the elderly: insights into pathogenesis and clinical decision-making.Journal of Aging Clinical and Experimental Research: 1-10.

[42] Qian M., Wu Q., Wu P., Hou Z., Liang Y., Benjamin J. and $\mathrm{Yu}$ H. (2020): Psychological responses, behavioral changes and public perceptions during the early phase of the COVID19 outbreak in China: a population based cross-sectional survey. Medrxiv Journal available at https://www.medrxiv.org/content/10.1101/2020.02.18.200244 $48 \mathrm{v} 1$ accessed on 20 March 2020

[43] Qian X., Ren R., Wang Y., Guo Y., Fang J., Wu D., Liu L., Han R. et al. (2020): Fighting against the common enemy of COVID-19: a practice of building a community with a shared future for mankind, Infectios Diseases of Poverty; 9 (34). https://doi.org/10.1186/s40249-020-00650-1.

[44] Rahman A. and Sathi J. (2020): Knowledge, Attitude, and Preventive Practices toward COVID-19 among Bangladeshi Internet Users, Electron J Gen Med; 17 (5): em245. https://doi.org/10.29333/ejgm/8223.

[45] Ranjan R. and Ranjan G. (2020): Knowledge Regarding Prevention of Novel Coronavirus (COVID-19): An Electronic Cross-Sectional Survey among Selected Rural Community. International Journal of Trend in Scientific Research and Development (IJTSRD); 4 (3): 422.

[46] Rinaldi L., Milione S., Fascione C., Pafundi C., Altruda C., Di Caterino M., Monaco L., Reginelli A., Perrotta F., Porta G. and Venafro M. (2020): Relevance of lung ultrasound in the diagnostic algorithm of respiratory diseases in a real-life setting: A multicentre prospective study. Respirology Journal, 25 (5): 535-542.

[47] Roy D., Tripathy S., Kar S., Sharma N., Verma S. and Kaushal V. (2020): Study of knowledge, attitude, anxiety \& perceived mental healthcare need in Indian population during COVID-19 pandemic, Asian J Psychiatr.; 51: 102083. Doi: 10.1016/j.ajp.2020.102083.

[48] Saadat S., Rawtani D. and Hussain Ch. (2020): Environmental perspective of COVID-19, available at https://www.sciencedirect.com/science/article/pii/S004896972 0323871 , accessed at 17 July, 2020.

[49] Salman M., Mustafa Z., Asif M., Zaidi H., Hussain Kh., Shehzadi N., Khan T. and Saleem Z. (2020): Knowledge, attitude and preventive practices related to COVID-19: a cross-sectional study in two Pakistani university populations, Drugs Ther Perspect; 9: 1-7. DOI: 10.1007/s40267-02000737-7.

[50] Satici B., Gocet-Tekin E., Deniz M. and Satici S. (2020): Adaptation of the Fear of COVID-19 Scale: Its Association with Psychological Distress and Life Satisfaction in Turkey. International Journal of Mental Health and Addiction: 1.

[51] Schoeman D. and Fielding C. (2019): Coronavirus envelope protein: Current knowledge, Virol J; 16 (1): 69.

[52] Sun P., Lu X., Xu C., Sun W. and Pan B. (2020): Understanding of COVID - 19 based on current evidence. Journal of medical virology, 92 (6): 548-551.

[53] Taghrir M., Borazjani R. and Shiraly R. (2020): COVID-19 and Iranian Medical Students; A Survey on Their RelatedKnowledge, Preventive Behaviors and Risk Perception. Archives of Iranian medicine Journal; 23 (4): 249-254.
[54] Wang H., Xiao X., Lu J., Chen Z., Li K., Liu H., Luo L., Wang M. and Yang Z. (2016): Factors associated with clinical outcome in 25 patients with avian influenza a (H7N9) infection in Guangzhou, China. BMC Infect Dis; 16 (1): 534.

[55] Wolf M., Serper M., Opsaasnick L., Conor R., Curtis L., Benavente J., Wismer G., Batio S., Eifler M., Zheng P., Russel A., Arvanitis M., Ladner D., Kwasny M., Persell S., Rowe T., Linder J. and Bailey S. (2020): Awareness, Attitudes, and Actions Related to COVID-19 Among Adults With Chronic Conditions at the Onset of the U.S. Outbreak, Annuls of Internal Medicine; V. 137, Issue, 2: 100: 109. https://doi.org/10.7326/M20-1239.

[56] World Health Organization (2020): Coronavirus disease 2019 (COVID-19) pandemic available at https://www.who.int/emergencies/diseases/novel-coronavirus2019 accessed on 15th March 2020.

[57] World Health Organization (2020): Clinical management of severe acute respiratory infection when novel coronavirus $(\mathrm{nCoV})$ infection is suspected. available at https://www.who.int/publications-detail/clinical-managementof-severe-acute-respiratory-infection-when-novel-coronavirus -(ncov)-infection-is-suspected. accessed at 28 June, 2020.

[58] World Health Organization (2020): 2019-nCoV outbreak is an emergency of international concern, available at http://www.euro.who.int/en/health-topics/healthemergencies/coronavirus-covid-19/news/news/2020/01/2019ncov-outbreak-is-an-emergency-of-international-concern, accessed at 1 April, 2020.

[59] World Health Organization (2020): COVID-19 situation update worldwide, as of 26 June 2020, available at: https://www.ecdc.europa.eu/en/geographical-distribution2019-ncov-cases, accessed at 26 June, 2020.

[60] World Health Organization (2020): Laboratory testing for coronavirus disease 2019 (COVID-19) in suspected human cases: interim guidance. available at: https://apps.who.int/iris/handle/10665/331329, accessed at 27 June, 2020.

[61] World Health Organization (2020): Middle East Respiratory Syndrome Coronavirus (MERS-CoV) -United Arab Emirates.available at https://www.who.int/csr/don/31-january2020-mers-united-arab-emirates/en/ accessed on 25 July, 2020.

[62] Yıldırım M., GeçerE. and Akgül Ö. (2020): The impacts of vulnerability, perceived risk, and fear on preventive behaviours against COVID-19. Psychology, Health \& Medicine: 1-9.

[63] Zegarra-valdivia J., Vilca B. and Guerrero A. (2020): Knowledge, perception and attitudes in Regard to COVID-19 Pandemic in Peruvian Population available at https://psyarxiv.com/kr9ya accessed at 24 July, 2020.

[64] Zhong B., Luo W., Li H., Zhang Q., Liu X., Li W and Li Y. (2020): Knowledge, attitudes, and practices towards COVID-19 among Chinese residents during the rapid rise period of the COVID-19 outbreak: a quick online cross-sectional survey. International Journal of Biological Science; 16 (10): 1745-1752.

[65] Zhu Z., Xu S., Wang H., Liu Z., Wu J., Li G., Miao J., Zhang C., Yang Y., Sun W. and Zhu S.(2020): COVID-19 in Wuhan: Immediate Psychological Impact on 5062 Health Workers. MedRxiv Journal available at https://www.medrxiv.org/content/medrxiv/early/2020/02/23/2 020.02.20.20025338 accessed on 22 march 2020. 